\title{
ANALYSIS OF THE RELIGIOUS TOURIST SENTIMENTS
}

\section{Angelina Njeguš ${ }^{1}$, Verka Jovanović ${ }^{1}$}

${ }^{1}$ Singidunum University, Belgrade, Serbia
Correspondence: Angelina Njeguš

e-mail:

anjegus@singidunum.ac.rs

\begin{abstract}
:
The purpose of this paper is to discuss how analytics tools can help in better understanding of religious tourist sentiments, especially when using religious tourism services. Today, information technologies (IT) are widely used in every segment of tourism, and have become its integral part. The benefits of IT usage in tourism are numerous. However, the focus in this paper is on applying sentiment analysis in religious text. The first part of the paper discusses how tourism has changed over time under the influence of IT computing. The second part presents the relationship between tourism, religion, learning and IT. Finally, the process and techniques of sentiment analysis are explained, as well as its application on religious text from five basic religious books. The results show that sentiments, such as trust, joy, fear and anticipation are dominant in the Bible.
\end{abstract}

\section{Keywords:}

sentiment analysis, religious tourism, information technologies.

\section{INTRODUCTION}

Millions of people travel around the world every day, for different purposes, such as for family or personal errands, social or recreational activities, work or work-related purposes, education, health, religious, or other (Bureau of Transportation Statistics, 2016). According to the UN World Tourism Organization (UNWTO), more than 1.2 billion people cross the border annually for touristic purposes (UNWTO, 2016). Indubitably, tourism has a significant impact on economic growth and job creation. Besides, it is an activity that is shared and loved by most people, and that boost self-expression and self-actualization. The rise of the free and independent travellers (FITs), who use online travel agents (OTAs), shared economy websites, low cost carriers, personal recommendation systems and other tourism-related applications, has changed the physiognomy of the market. Information technologies have pervaded every area of tourism, and become of the highest priority for tourism industry (UNWTO, 2016).

Information Technologies (ITs) have been transforming tourism industry since the 1980s (Fig. 1). From the first Computer Reservation Systems in the 1970s, and Global Distribution Systems in the late 1980s, followed by Internet and Internet services development in the late 1990s, mobile, and cloud computing development, the operational and strategic practices in the tourism industry have been dramatically transformed 
(Buhalis et al, 2008). When IBM's Watson supercomputer won the quiz show Jeopardy, in 2011, the era of cognitive computing started (Banavar, 2015). Today, cognitive systems are applied in tourism web sites personalization, tourism recommender systems, tourists' interaction systems that facilitate interactions between tourists and tourist places and other (Kardaras et al, 2013) (Adukaite, 2016).

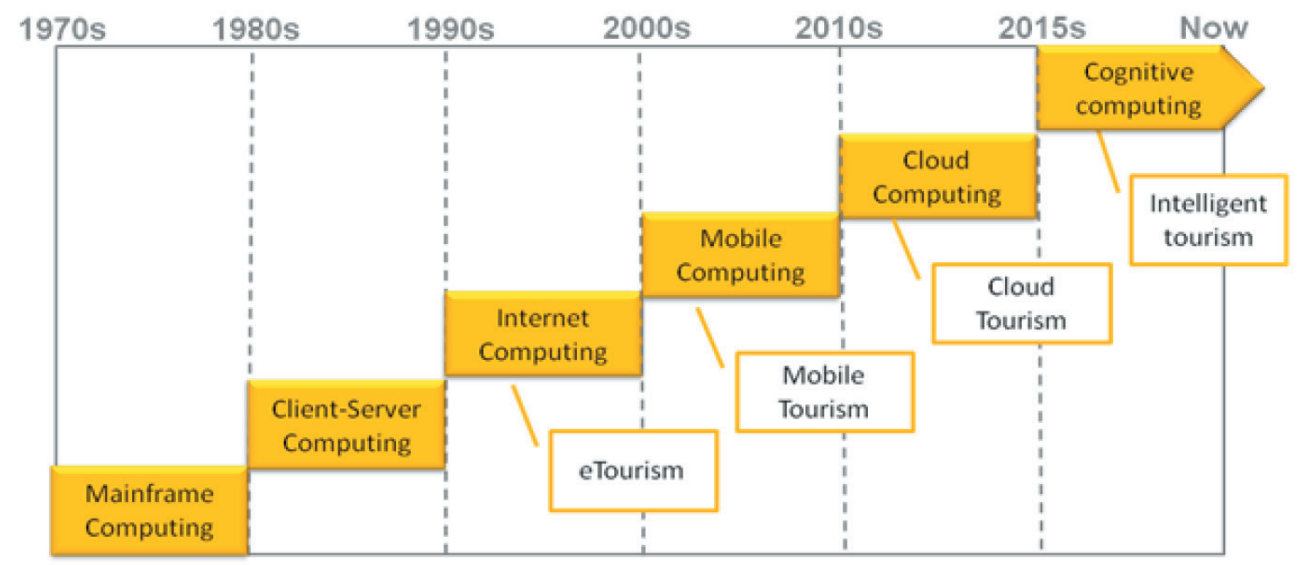

Fig. 1. The impact of IT computing on tourism

\section{RELIGIOUS TOURISM AND INFORMATION TECHNOLOGIES}

An important driver of tourism is religion, both for worshipping or knowledge reasons. Religious tourism can be defined as the type of travel motivated by faith/ religious or archaeological reasons (Petroman et al, 2015). Religious tourism, as an important segment of cultural tourism, includes pilgrimages, missionary travel, faith-based travel, education, conventions or rallies, retreats, monastery visits and guest stays, religious tourist attractions, leisure vacations, etc (Rinschede, 1992). The UNWTO estimates that 300 million tourists visit the world's major religious sites each year, and that 600 million people, around the world, travel for religious purposes (Raj et al, 2015) in order to visit holy places, religious centres, religious properties (UNESCO, 2017), or to participate in manifestations or mass religious events or just for humanitarian, spiritual, missionary, artistic, learning or leisure causes (Table 1).

Table 1. Examples of religious tourism activities ${ }^{\mathrm{a}}$

\begin{tabular}{ll}
\hline \multicolumn{1}{c}{ Motives } & \multicolumn{1}{c}{ Activities } \\
\hline Religious and secular motives & Pilgrimages, missionary, meditation, prayers \\
\hline Nature and exercise & Meditative hiking or walking, Yoga, Tai Chi \\
\hline Music & Chanting, singing hymns or prayers \\
\hline Counselling & Religious attractions, monastery visits and guest stays, faith-based camps \\
\hline Creativity & Icon painting, arranging flowers, colouring, ethno-gastronomy \\
\hline
\end{tabular}

a. adapted: Nieminen, 2012

According to the De Ascaniis et al. (2013), nearly 45\% of the religious tourism experiences are related to spiritual or religious life, and 39\% to artistic or aesthetic aspects of an attraction (Fig. 2). However, visits to the religious sites mostly have learning motives, both for believers, who want to have a better and deeper understanding of their faith, or visitors who are driven, not only by religion, but also by different cultures, lifestyles, customs, and other. 


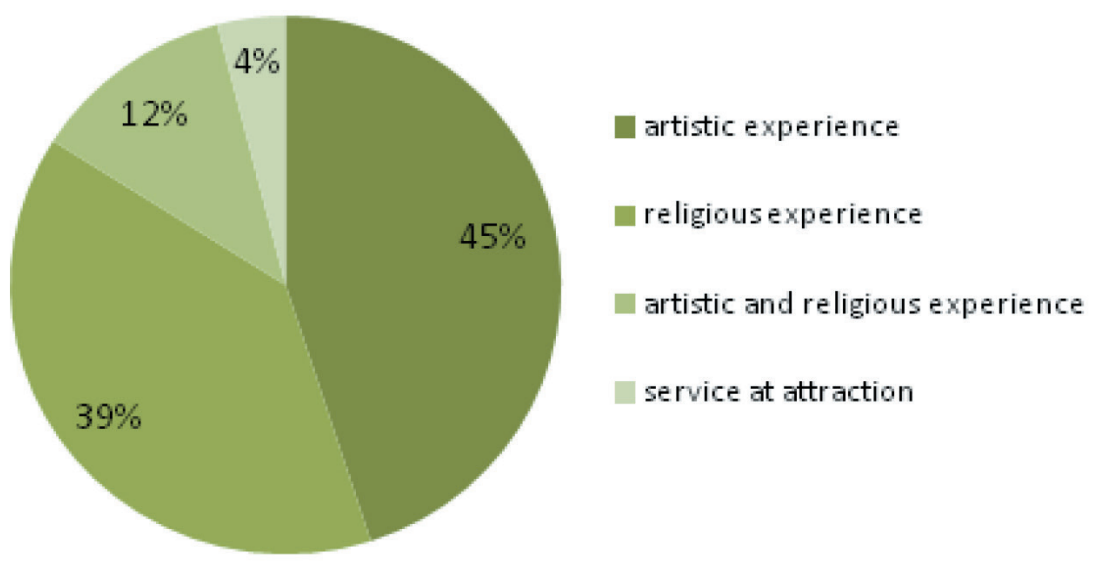

Fig. 2. Types of religious tourism experience (De Ascaniis et al, 2013)

Based on the above mentioned, there is an obvious relationship between Tourism, Religion, Learning and IT (Fig. 3). Some case studies that incorporate these aspects are: (1) mobile applications that enhance visitors' experience at the cathedrals - for example Armagh Cathedral's new tourist application (Armagh, 2017), (2) tweets analysis sent by pilgrims along the Camino de Santiago, that observe changes in mood (3) analysis of the usage of IT before, during, and after visits to Loreto
Sanctuary (4) IBM Watson application that guide the visitor through the Centres for Arts, Culture and Tourism, enriching their experience with digital content, improving customer satisfaction, and collecting their concerns and views regarding their experiences (Lanzarote, 2017) (Kelly, 2013), (5) travel recommendation, as a problem prediction based on the tourist's historical visiting sequences and supervised learning ( $Y u$ et al, 2017) (Zheng et al, 2016) and many others.

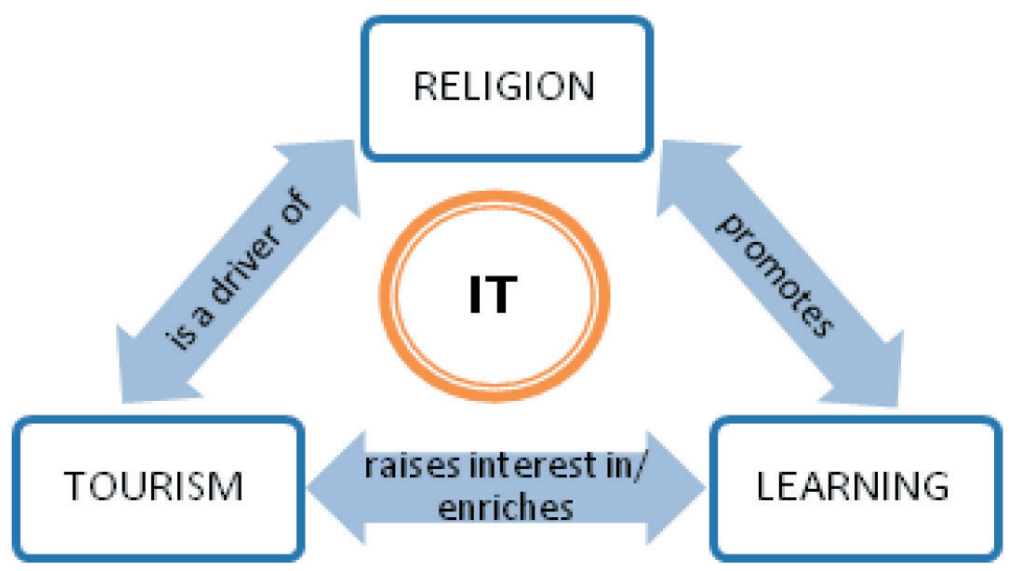

Fig. 3. Relationships between Tourism, Religion, and Learning supported by IT (De Ascaniis et al, 2013)

\section{ANALYSIS OF RELIGIOUS TOURISTS SENTIMENTS}

Sentiment analysis or opinion mining is a study of opinions, sentiments, attitudes, affects, emotions, subjectivities and other sentiments, expressed in text or images (Njegus et al, 2015). Since people's beliefs and perceptions are key influencers of their behaviour, with sentiment analysis, it is possible to get the following answers:
- How religious tourists feel or what their opinion about religion or some religious tourism service is;

- Which service they prefer more, and why;

- Which events, actions or individuals have driven positive or negative discussion, and what the arguments are;

- Insights into how some service should be modified; 
- How much visibility and media value of some religious topic is generated and in what tone;

- Segmentation of positive, neutral and negative posts;

- Segmentation of different basic emotions such as fear, anger, disgust, happiness, sadness or surprise from facial expressions extracted from images.

Sentiment analysis uses the natural language processor, and machine learning algorithms, to extract, and identify the sentiment from the text or image. According to Pawar, sentiment classification techniques can be roughly divided into Lexicon based or machine learning or hybrid approach (Fig. 4). Lexicon is a collection of sentiment terms and can be divided into dictionary based or corpus based approach.

In general, there are three main phases to implement sentiment analysis:
1. Pre-processing phase - include removal of irrelevant data from social conversations in order to prepare the text for further analysis. The textual data can be preprocessed by various activities, such as:

- Removal of non-English tweets, empty tweets, or re-tweets;

- Conversion to ASCII - many tweets contain nonstandard characters;

- Restoration of abbreviations - e.g. "wknd" to "weekend";

- Case normalization - entire document is converted into lowercase;

- Tokenization - splitting the text into personal terms or tokens;

- Stemming - contains the recognition and elimination of suffixes, prefixes, and unsuitable pluralizations.

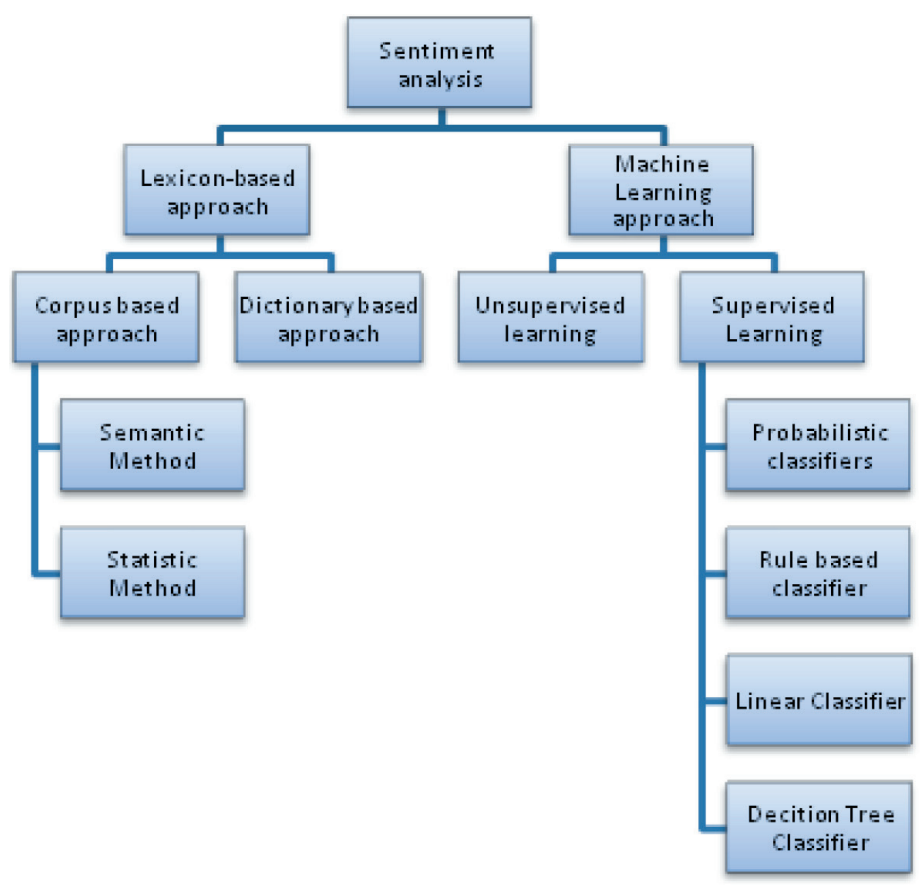

Fig. 4. Sentiment analysis techniques (Pawar et al, 2015)

2. Feature extraction and selection phase - include understanding a natural language (social conversation is full of sarcasm, irony, slang, misspelled words, and different languages that algorithms are still not capable to interpret), and understanding visual content (today more than $90 \%$ of social posts contain images and videos). Some steps include:

- Lexicon features - each word is classified into positive, negative or neutral lexicon, and it is compared with predefined libraries;
- Part of speech features - each word is tagged as noun, adverb, adjective, or other;

- Micro-blogging features - online slang dictionaries can be used for detection of sentiments in abbreviations or intensifiers.

3. Classification and visualisation - any of the traditional mining algorithms can be used for classification, e.g. decision trees, ensembles, support vector machines, naive Bayes, etc. 
Features of the sentiment analysis are (Pawar et al, 2015):

- Terms frequency - gives binary weighting to the words or uses the term frequency weights;

- Parts of the speech - finding adjectives from the text, as important indicators of sentiments;

- Opinion words and phrases - these words express opinion, e.g. good or bad, like or hate.

In the project Gutenberg (https://www.gutenberg. org/) posted on Kaggle (https://www.kaggle.com), five religious books were provided in order to encourage text mining, sentiment analysis, or other analysis. These five books are: The King James Bible, The Quran, The Book of Mormon, The Gospel of Buddha, and Meditation, by Marcus Aurelius. According to Shashank (2016), results of sentiment analysis of all religious texts provided in these books, are presented in the Figure 5. In the Bible, the total number of words reflecting trust is the highest, followed by words reflecting joy, fear and anticipation. However, there are also words that invoke disgust, sadness, and anger, and at the least surprise. In the book Gospel of Buddha, the most words represent trust, joy and anticipation.

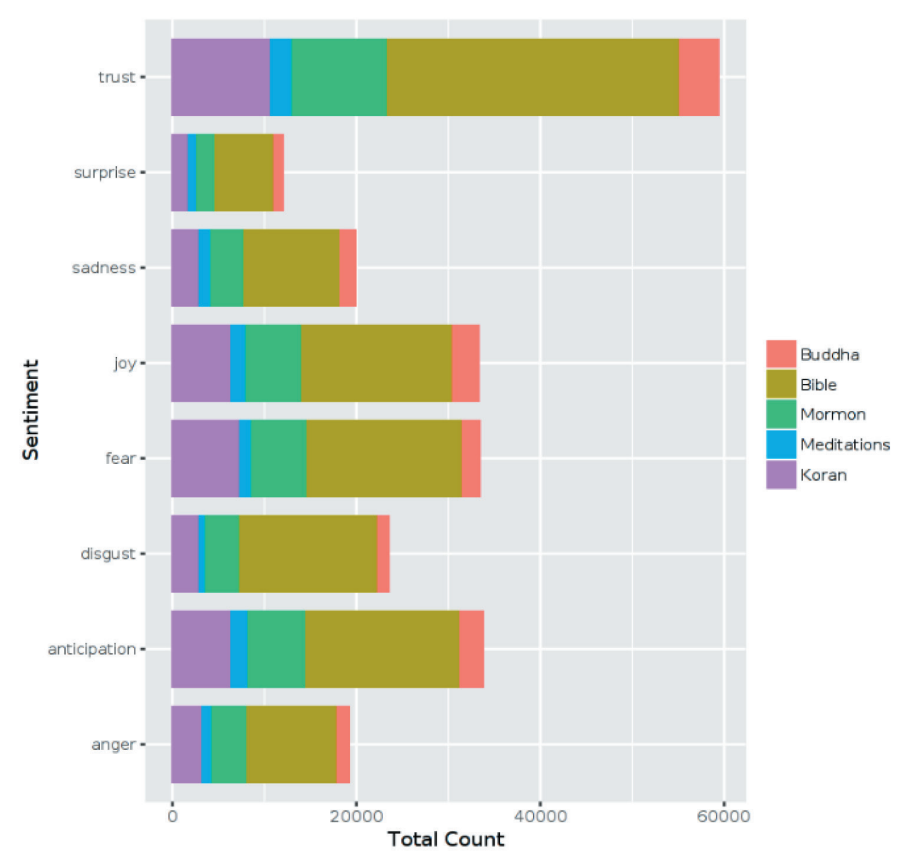

Fig. 5. Sentiment analysis of all religious texts (Shashank, 2016)

\section{CONCLUSION}

Religious tourism is the one of the earliest and most important forms of tourism. It has not been only a call to spirituality, but also a major economic driver. With advancement of information technologies, the religious tourists become equipped with smart gadgets, to freely express their emotions on social media, using text, images or videos. In order to analyse sentiments among religious tourists, sentiment analysis systems are important tool. Besides examining sentiment analytics techniques, this paper explains the analysis of the religious text from five books. The results demonstrate that the main emotions are trust, joy, fear and anticipation, and words reflecting these emotions are most mentioned in the Bible.

\section{REFERENCES}

Adukaite, A. et al. (2016). Pilgrims in the Digital Age: a research manifesto. International Journal of Religious Tourism and Pilgrimage. 4(3). Communication Technologies in Religious Tourism and Pilgrimage. 1-5.

Armagh. (2017). Archdiocese of Armagh. Retrieved 18 May 2017 from http://www.armagharchdiocese. org/armagh-cathedrals-launch-tourist-app.

Banavar, G. S. (2015). Watson and the Era of Cognitive Computing. 2015 IEEE International Conference on Pervasive Computing and Communications (PerCom). pp. 95-95. 
Buhalis, D., Law, R. (2008). Progress in information technology and tourism management: 20 years on and 10 years after the Internet-The state of eTourism research. Tourism Management. 29(4 ), 609-623.

Bureau of Transportation Statistics. (2016). Passenger Travel Facts and Figures 2016, U.S. Department of Transportation. Retrieved 13.05.2017 from https:// www.rita.dot. gov/bts/sites/rita.dot.gov.bts/files/ PTFF_2016_full.pdf().

De Ascaniis, S., \& Cantoni, L. (2013). Artistic and religious experiences in online travel reviews on Saint Paul outside the walls (Rome). Proceeding of ICOT 2013, International Conference on Tourism. 5-8, 160-173.

Kardaras, D. K., Karakostas, B., Mamakou, X. J. (2013). Content presentation personalization and media adaptation in tourism web sites using Fuzzy Delphi Method and Fuzzy Cognitive Maps. Expert Systems with Applications. 40(6), 2331-2342.

Kelly III, J. E., Hamm, S. (2013). Smart Machines: IBM's Watson and the Era of Cognitive Computing. Columbia University Press.

Nieminen, K. (2012). Religious Tourism - a Finnish Perspective. Master thesis. Haaga-Helia University of Applied Sciences.

Njegus, A., Jovanovic, V., Veinovic, M. (2015). Challenges and opportunities of Big Data Analytics in the hotel industry. X International Scientific and Professional Conference "Hotelska kuća" 2015. HORES. Zlatibor, 85-93.

Pawar, K. K., Shrishrimal, P. P., Deshmukh, R. R. (2015). Twitter Sentiment Analysis: A Review. International Journal of Scientific and Engineering Research. 6(4), 958-964.
Petroman, C., Petroman I., Ciolac, R., Marin, D. (2015). Types of Christian Tourism. Animal Science and Biotechnologies. 48(2), 203-206.

Raj, R., Griffin, K. (2015). Religious Tourism and Pilgrimage Management: An International Perspective. 2nd edition. CAB International: London, UK.

Rinschede, G. (1992). Forms of Religious Tourism. Annals of Tourism Research. 19, 51-67.

Shashank, V. (2017). Sentiment Analysis of Religious Text. Retrieved 23.05.2017 from https://www.kaggle.com/ver- mashashank/sentiment-analysis-ofreligious-texts.

UNESCO (2017). Heritage of Religious Interest. UN ESCO Initiative on Heritage of Religious Interest. Retrieved 13.05.2017 from http://whc.unesco.org/ en/religious- sacred-heritage/.

UNWTO (2016). Network of religious tourism. UNWTO Project brief. Retrieved 13.05.2017 from http ://cf.cdn.unwto.org.

Yu, Y., Wand, Y., Gao, S., Tang, Z. (2017). Statistical Modeling and Prediction for Tourism Economy Using Dendritic Neural Network. Computational Intelligence and Neuroscience. 2017. Hindawi Publishing Corp. Retrieved 23.05.2017 from https://www. ncbi.nlm.nih.gov/pmc/articles/PM C5299217/pdf/ CIN2017-7436948.pdf.

Zheng, S., Liu, Y., Ouyang, Z. (2016). A Machine Learning-based tourism path prediction. Proceedings of CCIS2016, 38-42. 